\title{
Is CSF neurofilament light chain measurement relevant for MS?
}

Makoto Matsui, MD, PhD

Neurol Neuroimmunol Neuroinflamm 2020;7:e886. doi:10.1212/NXI.0000000000000886

MS is a chronic inflammatory demyelinating disease of the CNS in which an autoimmune etiology targeting CNS myelin is implicated. Tremendous efforts to search for biomarkers that potentially reflect the inflammatory process in the CNS have been made, although MRI was the only reliable clinical method for that purpose until recent findings showing the usefulness of the measurement of neurofilaments. Neurofilament release is assumed to be a consequence of axonal damage, with some components appearing in the CSF and then in blood at extremely low concentrations. ${ }^{1}$ An ELISA for CSF neurofilament light chain protein (NfL) has shown to give consistent results as a marker for MS disease activity, suggesting it may be useful as a measure of MS treatment response. ${ }^{1}$

NfL levels in the CSF can predict a sustained status of no evidence of disease activity 3, namely, no clinical relapse, brain MRI activity, or progression in the Expanded Disability Status Scale (EDSS). ${ }^{2}$ Another study showed that this CSF marker not only identified patients with clinically isolated syndrome who later developed $\mathrm{MS}^{3}$ but also patients with relapsing-remitting MS (RRMS) who showed progression in the EDSS or converted to secondary progressive MS at 5-year follow-up. ${ }^{4}$ It has also been reported that the potent disease-modifying drug (DMD) natalizumab markedly reduced axonal damage when assessed using CSF NfL levels. ${ }^{5}$ Furthermore, measurement of CSF NfL levels may serve as an effective tool for monitoring the treatment effects of fingolimod. ${ }^{6}$ Therefore, NfL in the CSF has been established as a biomarker for the assessment of prognosis and treatment efficacy in patients with MS. However, it is still unclear whether CSF NfL levels can be used for decision-making regarding MS treatment.

In this issue of Neurology ${ }^{\circledR}$ Neuroimmunology \& Neuroinflammation, Reyes et al..$^{7}$ attempted to address some of the above-mentioned issues. These authors enrolled 203 patients with MS (RRMS 58\%, progressive MS 42\%), of whom 169 (83\%) were not treated with any DMD at the time of enrollment (baseline). Study participants were assessed for disease activity in terms of occurrence of relapse and/or sustained disability progression, MRI findings, and NfL level in the CSF. However, although CSF NfL levels were determined, no specific algorithm for treatment selection according to $\mathrm{NfL}$ results was used, and thus, the treatment decision-making process was primarily dependent on clinical and/or MRI findings under the discretion of MS consultants. Thus, the effect of CSF NfL measurements on treatment choice was only modest. The investigators classified final treatment decisions into 2 categories: "no treatment/no escalation," which included patients not started with a DMD $(\mathrm{n}=36)$ or those who remained with their previous $\operatorname{DMD}(\mathrm{n}=26)$, and "treatment/escalation," which included treatment-naive patients for whom medication with any DMD was begun $(\mathrm{n}=129)$ and patients whose DMD at study enrollment was changed to a more potent treatment $(n=12)$. The EDSS was assessed at baseline and at least 1 year after the treatment decision. The relevance of high or low levels of CSF NfL in the decisionmaking process was retrospectively analyzed by comparing median values obtained among subgroups in the 2 categories. The "no treatment" and "no escalation" subgroups showed low median values ( 264.5 and $269 \mathrm{pg} / \mathrm{mL}$, respectively), whereas the "escalation" subgroup showed the highest median value $(696 \mathrm{pg} / \mathrm{mL})$ and the "treatment" subgroup had the intermediate values (above or below $400 \mathrm{pg} / \mathrm{mL}$ ). However, the median EDSS score at baseline did not change for at

\author{
Correspondence \\ Dr. Matsui \\ veritasm@kanazawa-med.ac.jp
}

\section{RELATED ARTICLE}

CSF neurofilament light

chain testing as an aid to

determine treatment

strategies in MS

Page e880 
least 1 year within the 2 subgroups of each category: 2.5 vs 2.5 in the "no treatment/no escalation" group and 4 vs 4.75 in the "treatment/escalation" group, with the median EDSS score change of 0 in both. These findings suggest that results of NfL measurement in the CSF affected treatment choice, despite guidelines for its use were not available. In addition, those decisions seemed to be successful in 1-year follow-up results. This study demonstrates the potential utility of CSF NfL levels in individual patients with MS as a biomarker for treatment decision-making independent of clinical and MRI findings. Because CSF samples are routinely collected during the initial assessment or as part of the studies used in the differential diagnosis of MS, the availability of CSF for the measurement of NfL does not constitute a limitation.

Readers of this article may wonder about the need of NfL CSF studies considering the fact that determination of NfL levels in blood has been established as a feasible biomarker of MS treatment response, based on findings of a 2-year follow-up study $^{8}$ and another study showing its use for the prediction of 10-year MRI disease activity. ${ }^{9}$ Thus, it is important to ask why NfL levels in the CSF should also be determined. Although the advantages of blood samples include easy collection and repeatability, blood NfL measurements only show potentially useful information when samples from a large number of patients are considered, the usefulness in individual cases is limited because of the narrow range of results assessed $(10-100 \mathrm{pg} / \mathrm{mL})^{8-10}$ and a possible contribution of comorbidities affecting the peripheral nervous system. ${ }^{1}$ Ethnic differences may also be a concern, although CSF and blood NfL measurements conducted in Japanese patients with MS showed comparable results with those of patients included in studies from western countries. ${ }^{10}$

In summary, measurement of NfL levels in the CSF still has an important role in MS clinics, and the value obtained from a 1-time lumbar puncture may provide guidance for initial treatment. The work by Reyes et al. is an important first step toward a well-designed follow-up study conducted with a large-scale cohort over at least a 5-year period to clarify the relevance of this unique biomarker.

\section{Study funding}

No targeted funding reported.

\section{Disclosure}

M. Matsui has received support from a Health and Labour Sciences Research Grant on Intractable Diseases [H29Nanchitou (Nan)-Ippan-043] and JSPS KAKENHI (grant ID 18059049), as well as research support from the following companies: Astellas Pharma, Daiichi-Sankyo, Eisai, Japan Blood Products Organization, Kyowa Kirin, Mitsubishi Tanabe Pharma, Otsuka Pharmaceutical, Pfizer, and Takeda Pharmaceutical, along with speaking fees and/or honoraria from Alexion Pharma, Astellas Pharma, Biogen Japan, CSL Behring, Eisai, Japan Blood Products Organization, Kyowa Kirin, Nihon Pharma, Ono Pharmaceutical, Sumitomo Dainippon Pharma, Takeda Pharmaceutical, Teijin, and UCB Japan. Go to Neurology.org/NN for full disclosures.

\section{References}

1. Khalil M, Teunissen CE, Otto M, et al. Neurofilaments as biomarkers in neurological disorders. Nat Rev Neurol 2018;14:577-589.

2. Håkansson I, Tisell A, Cassel P, et al. Neurofilament levels, disease activity and brain volume during follow-up in multiple sclerosis. J Neuroinflammation 2018;15:209.

3. Arrambide G, Espejo C, Eixarch H, et al. Neurofilament light chain level is a weak risk factor for the development of MS. Neurology 2016;87:1076-1084.

4. Bhan A, Jacobsen C, Myhr KM, et al. Neurofilaments and 10-year follow-up in multiple sclerosis. Mult Scler J 2018;24:1301-1307.

5. Gunnarsson M, Malmeström C, Axelsson M, et al. Axonal damage in relapsing multiple sclerosis is markedly reduced by natalizumab. Ann Neurol 2011;69:83-89.

6. Kuhle J, Disanto G, Lorscheider J, et al. Fingolimod and CSF neurofilament light chain levels in relapsing-remitting multiple sclerosis. Neurology 2015;84:1639-1643.

7. Reyes S, Smets I, Holden D, et al. CSF neurofilament light chain testing as an aid to determine treatment strategies in MS. Neurol Neuroimmunol Neuroinflamm 2020;7: e880. doi: 10.1212/NXI.0000000000000880.

8. Kuhle J, Kropshofer H, Haering DA, et al. Blood neurofilament light chain as a biomarker of MS activity and treatment response. Neurology 2019;92:e1007-e1015.

9. Chitnis T, Gonzalez C, Healy BC, et al. Neurofilament light chain serum levels correlate with 10-year MRI outcomes in multiple sclerosis. Ann Clin Trans Neurol 2018;5:1478-1491.

10. Watanabe M, Nakamura Y, Michalak Z, et al. Serum GFAP and neurofilament light as biomarkers of disease activity and disability in NMOSD. Neurology 2019;93: e1299-e1311. 


\title{
Neurology $^{\odot}$ \\ Neuroimmunology \& Neuroinflammation
}

\author{
Is CSF neurofilament light chain measurement relevant for MS? \\ Makoto Matsui \\ Neurol Neuroimmunol Neuroinflamm 2020;7; \\ DOI 10.1212/NXI.0000000000000886
}

This information is current as of September 14, 2020

\section{Updated Information \& Services}

References

Subspecialty Collections

Permissions \& Licensing

Reprints including high resolution figures, can be found at:

http://nn.neurology.org/content/7/6/e886.full.html

This article cites 10 articles, 1 of which you can access for free at: http://nn.neurology.org/content/7/6/e886.full.html\#\#ref-list-1

This article, along with others on similar topics, appears in the following collection(s):

All Clinical Neurology

http://nn.neurology.org//cgi/collection/all_clinical_neurology

All Demyelinating disease (CNS)

http://nn.neurology.org//cgi/collection/all_demyelinating_disease_cns Multiple sclerosis

http://nn.neurology.org//cgi/collection/multiple_sclerosis

Information about reproducing this article in parts (figures,tables) or in its entirety can be found online at:

http://nn.neurology.org/misc/about.xhtml\#permissions

Information about ordering reprints can be found online:

http://nn.neurology.org/misc/addir.xhtml\#reprintsus

Neurol Neuroimmunol Neuroinflamm is an official journal of the American Academy of Neurology.

Published since April 2014, it is an open-access, online-only, continuous publication journal. Copyright

Copyright $\odot 2020$ The Author(s). Published by Wolters Kluwer Health, Inc. on behalf of the American

Academy of Neurology.. All rights reserved. Online ISSN: 2332-7812.

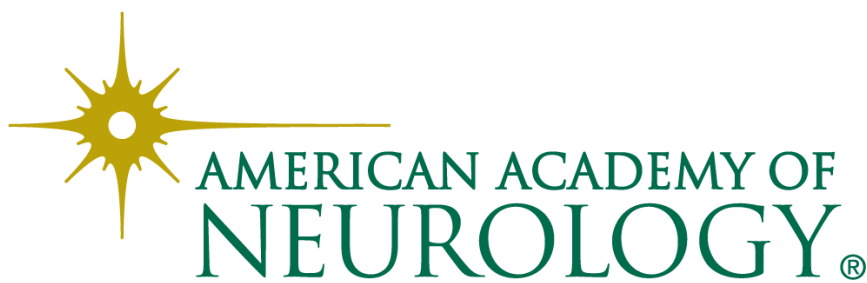

